\title{
LA BELLEZA ENIGMÁTICA DEL FUEGO. ROBBE- GRILLET MÁS ACÁ Y MÁS ALLÁ DE BARTHES
}

\author{
Bruno Grossi \\ Universidad Nacional del Litoral \\ Consejo Nacional de Investigaciones Científicas y Técnicas \\ brunomilang@gmail.com
}

Resumen: La relación de RobbeGrillet con Barthes marca uno de los episodios más extravagantes de las relaciones ambiguas entre la literatura y la crítica literaria. El siguiente trabajo propone por lo tanto desandar algunos de los equívocos en torno al "objetivismo", analizar cómo condujo a que una determinada lectura terminara por hipostasiarse hacia toda la obra robbegrilleteana y postular a su vez una interpretación alternativa a aquellos textos a partir de intervenciones laterales (discusiones en coloquios, entrevistas, causeries) de Robbe-Grillet. Finalmente, una crítica estética al estructuralismo se derivará del diálogo crítico entre ambos autores.

Palabras clave: Robbe-Grillet, Barthes, Estructuralismo, Experiencia estética, Objetivismo.

\begin{abstract}
Robbe-Grillet's relationship with Barthes marks one of the most extravagant episodes in the ambiguous relations between literature and literary criticism. The following paper therefore proposes to retrace some of the misunderstandings surrounding "objectivism", to analyze how it led to a certain reading that ended up hypostasizing Robbe-Grillet's entire oeuvre, and to postulate an alternative interpretation of those texts based on lateral interventions (discussions at conferences, interviews, causeries) by Robbe-Grillet. Finally, an aesthetic critique of structuralism will be derived from the critical dialogue between the two authors.
\end{abstract}

Keywords: Robbe-Grillet, Barthes, Structuralism, Aesthetic experience, Objectivism. 
La relación de Robbe-Grillet con Barthes marca uno de los episodios más extravagantes de las relaciones ambiguas entre la literatura y la crítica literaria. Este caso ejemplar permite leer, si se quiere, los modos en los que una obra y unos ensayos pueden dialogar, potenciarse, distanciarse y traicionarse entre sí, volviéndose verdaderos campos minados en los que se vuelve imposible transitar sin chocarse con zonas lúcidamente delimitadas o deliberadamente oscurecidas, llenas de trampas o atajos, ingeniosas invenciones o cínicas tácticas imperiales. Una estratificación de capas y capas de interpretaciones, de significaciones fluctuantes a través del tiempo que definen, en cierta medida, las obras de ambos autores, la potencia de sus actos y simultáneamente las disputas institucionales en las que se inscriben. Si interesa a pesar de todo recorrer tal encrucijada, es para desandar algunos de sus equívocos, analizar cómo condujeron a que una determinada lectura terminara por hipostasiarse hacia toda la obra robbegrilleteana y leer las posibilidades de entredecir una vía alternativa que permita reconocer y movilizar las fuerzas en disputa en su interior. Sin embargo, es una reflexión mayor sobre la propia crítica literaria la que se desprende de tales discusiones: de allí que a partir del contraste con otros hermeneutas de Robbe-Grillet (los modos en los que este polemiza teóricamente de igual a igual con aquellos), no solo podemos iluminar aspectos silenciados de sus textos, sino que se nos permite apreciar las posibilidades, pero sobre todo los límites inscriptos en el proyecto estructuralista. El retorno final a Barthes - por los coqueteos y resistencias con los que este se relacionó con dicho paradigma 
- nos deja apreciar mejor una ética posible de lectura, tal como Robbe-Grillet la imagina para sí y para la literatura en general.

Es por ello que uno podría decir que las relaciones amistosas e intelectuales entre ellos estuvieron signadas por un cariño que no reñía con la sospecha o la recriminación sorda. De hecho, Robbe-Grillet era capaz de declarar, en el medio de un coloquio dedicado a Barthes, su más afectuosa admiración por los escritos de aquel (al punto de confesar que podría recitar fragmentos enteros de El grado cero de la escritura de memoria, de citarlo en sus propios ensayos y clases sobre literatura o de elevar su estatus a la categoría misma de novelista moderno, es decir a la de un creador que excede, por lo singular de los procedimientos utilizados, el dominio de lo meramente conceptual), como de sugerir los efectos ambiguos que esos ensayos iniciales había tenido sobre su obra posterior. Situación paradójica la de la recepción que el propio RobbeGrillet habría de constatar con precisión, con turbio énfasis, en diversas intervenciones a lo largo de los años: si por un lado manifestaba siempre un agradecimiento profundo ante el espaldarazo crítico dado por Barthes, en tanto el valor de modernidad que transmitían esos ensayos (por las posibilidades que sugerían en términos de técnica, estructura y visión de mundo novelesca) había causado un efecto de contagio inmediato en el campo, generando una cuasi ola expansiva que lo convirtió en el transcurso de una década en una de las vedettes de la literatura internacional; por el otro no dejaba de señalar con perplejidad a veces, con acritud otras, lo parcial, reductor y equívoco de la lectura de aquel (Robbe-Grillet, 2001, p. 500). Aun cuando admitiera la polisemia de todo texto 
-incluido el suyo- y evitara recaer en una crítica análoga a la que Picard había hecho al propio Barthes, el reproche de RobbeGrillet tenía su momento de verdad: es que, en cierto sentido, a pesar de las constantes, múltiples y radicales transformaciones que su obra había ido experimentando durante cincuenta años, para el gran público este nunca dejó de ser el escritor objetivo, austero y racional de los años cincuenta que Barthes había caracterizado indirectamente. No es que Barthes leyera mal, adulterara o tuviera mala fe, pero la taxatividad seductora de su retórica y la univocidad de su lectura terminó por convertirse en la doxa irrefutable en torno de la obra.

Paradójicamente, tomando en los años cincuenta mis propias novelas como máquinas infernales que le permitían ejercer el terror, trataría de reducir sus desplazamientos maliciosos, sus fantasmas en filigrana, sus autoborramientos, sus aperturas, a un universo cosista que, por el contrario, solo afirmaría su solidez, objetiva y literal. Por supuesto, este aspecto estaba presente en los libros (y en mis propias observaciones teóricas), pero como uno de los dos polos irreconciliables de una contradicción (RobbeGrillet, 2009, p. 39). ${ }^{1}$

En este sentido, Barthes bien podía leer la construcción de los objetos en Les gommes sin reconocer el mito de Edipo que organizaba estructuralmente el relato o escribir diez páginas sobre el vaciamiento de la anécdota de Le voyeur sin darle importancia al crimen sexual; lo que llevaba a pensar a RobbeGrillet que sus novelas se habían vuelto, en las manos de Barthes, menos un objeto estético que uno táctico, con el cual

\footnotetext{
${ }^{1}$ Las traducciones de los textos consignadas en francés son propias.
} 
este reanudaba y extenuaba su búsqueda del grado cero y la "escritura blanca". Pero para hacerlo, Barthes debía realizar ciertamente una operación de saneamiento de los textos. Como buen terrorista "había elegido solo una de las aristas del texto, la más afilada, para utilizarme como un arma blanca" (RobbeGrillet, 2009, p. 39). Tapándose los ojos ante los fantasmas sexuales escondidos bajo el aparente cuadro hiperrealista, la lectura de Barthes construyó un mundo a la medida de sus propios intereses, en el que todo el valor de la negatividad de Robbe-Grillet consistía básicamente en el poder de sustracción o superación de la fascinación de la fábula novelesca vía la multiplicación de objetos, la retórica neutra y el adelgazamiento de la anécdota. La modernidad de RobbeGrillet, según Barthes, radicaba precisamente en su capacidad de resistencia a los esquematismos que conducían a la identificación y al ilusionismo que instauraba el realismo.

Si — tal como manifestó Robbe-Grillet en una de las discusiones de los coloquios de Cerisy_ lo importante de una lectura no es la supuesta verdad o falsedad de una interpretación, sino su potencia productora o el tipo de descendencia que deja tras sí (Ricardou y Van Rossum-Guyon, 1976), la operación de Barthes debe reconocerse tanto por la fuerza de su persuasión como, por otro lado, por su valor adherente, esto es, por la serie de semas que terminó por superponer a la poética del otro. Pero por eso mismo cuando, en la prosecución de la obra, otras dimensiones latentes en los textos de Robbe-Grillet cobraron relevancia, en el momento en que, por ejemplo, los juegos estructurales de Dans le labyrinth comenzaron a cuestionar la pretendida solidez del mundo 
objetivista; o la dimensión subjetiva, imaginaria, fantasmal de L'Année dernière à Marienbad se hizo demasiado visible, ocupando la extensión misma de la anécdota, Barthes tuvo necesariamente que recapitular, no quedándole otro recurso que señalar las inconsistencias con las supuestas premisas previas.

$\mathrm{Al}$ aceptar hacer un filme, Robbe-Grillet, el escritor de la pura visión verbal $[\ldots]$ elige rehabilitar una literatura de adjetivos, por muy bellos que sean $[\ldots]$ al relatar una historia -de amor, de muerte, de sueño o de adulterio, da lo mismo-, elige contra todas las otras historias del mundo, permitiéndonos así preferir el mundo a esa historia: su literatura ya no es entonces ontológicamente reaccionaria, sino que se vuelve ideológicamente reaccionaria (Barthes, 2003, p. 150).

No es que la obra de Robbe-Grillet cambiara drásticamente o adquiriera de pronto una serie de valores que contradijeran los textos anteriores, es que la evidencia que el film trajo consigo hizo imposible dejar de ver el carácter alucinado de la escritura, la violencia silenciosa tras la estructura y el erotismo fascinante de ese mundo. Se vuelve sugestivo, en algún punto, cuánto de la interpretación de Barthes se deriva de su experiencia íntima de lectura, ya que él mismo considera que la literatura de Robbe-Grillet, como toda tentativa de vanguardia o experimental, tiene algo de deceptivo y que su valor no pasa necesariamente por el placer que ocasiona. ${ }^{2}$ Es la tensión que

${ }^{2}$ Cuando Barthes sostiene que "[Robbe-Grillet] aspira a descondicionar la novela de sus reflejos tradicionales, a hacerles expresar un mundo sin cualidades; la novela es el ejercicio de una libertad absoluta (quedando bien entendido que el ejercicio no es forzosamente un logro de grandes resultados" (1973, p. 124) no habría que leer allí ni siquiera una ironía, sino una confesión de la escisión fundamental entre el crítico y el lector. 
se deja leer en él: el vanguardismo táctico lo lleva a identificar y defender el valor estético-teórico de Robbe-Grillet; su clasicismo disimulado a distanciarse afectivamente de él. Es como si, frente a la radicalidad formal que frustra su experiencia placentera de lectura, convirtiera su vago aburrimiento en motivo de destrucción de las categorías burguesas que dominan el pensamiento sobre la literatura. Las novelas de Robbe-Grillet, a pesar de la postulación barthesiana del universo extra-moral con la que se construyen, son usadas convenientemente para ejercer la crítica, el distanciamiento y la desmitificación; volviéndolas, en suma, un avatar radicalizado de aquello que ya hallaba en un escritor tan ajeno como Brecht. Pero tal lectura se consigue a precio de negar el afecto perverso que anima la literatura de Robbe-Grillet y que conduce, no sin rodeos, a una experiencia ambigua moralmente.

No a otra cosa apuntaba Genette cuando, en una especie de mea culpa colectiva, señaló que "releídas apresuradamente bajo esta nueva luz, las novelas anteriores revelaban una turbadora irrealidad, antes insospechada" (1966, p. 78). De allí que cuando en un pasaje de Le voyeur leemos que Mathias "retrocedió un metro, para ver mejor el conjunto; pero cuando más lo miraba más le parecía impreciso, cambiante e incomprensible" (Robbe-Grillet, 1969, p. 164) se vuelve difícil no leer en él un gesto programático après-coup. El fragmento no solo indica indirectamente una posible posición hermenéutica ante la obra (la necesidad de establecer una distancia ante la institucionalización del conjunto que permita apreciarlo mejor), sino que entredice la posición estética del propio Robbe-Grillet frente al mundo. El carácter móvil y perturbador de eso que se 
presenta como sólido es lo que se hallaba neutralizado en la lectura de Barthes. A pesar del encanto innegable de unos ensayos en los que se podía percibir el movimiento mismo del pensamiento, las distintas piruetas y hallazgos conceptuales frente a las dificultades que encontraba a cada paso (muchas expresiones y giros retienen algo de ese asombro, de estar entrando en verdadera terra incognita, de enfrentarse a una serie de posibilidades, resistencias y enigmas inéditos), se volvía también evidente que, frente a la necesidad de abrirse camino en la oscuridad, este debía arrojar luz en una dirección, ${ }^{3}$ omitiendo necesariamente otras. Amén de lo tentativo, fragmentado y apriorístico del análisis de Barthes, el propio Robbe-Grillet señalaba la confusión generalizada en torno al supuesto objetivismo por aquel analizado y como este no era más que el resultado de homologar cándidamente lo cósico a lo objetivo. Si bien "Literatura objetiva" y "Literatura literal" tendían de forma obsesiva hacia el análisis de los objetos presentes en los textos, su forma inédita de presentación y el lugar estructuralmente nuevo que ocupaban allí, Barthes terminaba por atribuir tales descripciones a una conciencia desafectada e impersonal que solamente se contentaba con constatar las superficies, describir los contornos o medir las distancias, posibilitando que el procedimiento visual suprimiera todo contenido humoral (1973, p. 39) y que la técnica maridara con el ideal de la objetividad del discurso científico. Aun así, no menos cierto era que Robbe-Grillet, contradiciendo su

\footnotetext{
${ }^{3}$ ¿No es ese el principio mismo de la anamorfosis de Crítica y verdad, asignar un sentido, una dirección, una unidad al texto, o al menos una unidad que, atendiendo a la heterogeneidad, involucre la mayor cantidad de masa textual? (Barthes, 2010, p. 72).
} 
propio reproche, no dejó nunca de señalar que Barthes no permitía que olvidemos, desde el epígrafe mismo del primer ensayo, que lo que sus propios textos hacían era un giro hacia el objeto, esto es, "una literatura de sujeto, como toda la literatura, pero vuelta hacia el objeto" (Robbe-Grillet, 2001, p. 501). Poniendo entre paréntesis la interioridad, la novela se volvía la percepción directa, no mediada por otros sistemas de valores, de lo que rodea efectivamente al hombre. Una lectura banal -no explicitada, pero cuanto menos sugerida en los textos- pretendía señalar que las novelas de Robbe-Grillet, desentendiéndose de las aventuras y los destinos humanos, priorizaban los objetos a las personas, o que al describirlos con técnicas similares terminaba cuanto menos por igualarlos. ${ }^{4} \mathrm{El}$ ocaso progresivo del personaje novelesco y los intentos de dar una visión material de las cosas con independencia del lenguaje antropomórfico no hizo sino reforzar aquella lectura, al margen de las mediaciones, matices o inconsistencias que señalaban la imposibilidad de franquear el punto de vista subjetivo. A pesar de todo Barthes hallaba así algo verdadero: la preocupación de Robbe-Grillet por el objeto trascendía la mera existencia de las cosas tal como podía colegirse del uso funcional en Balzac, verosímil en Flaubert, sociológico en Perec o metafísico en Ponge, aun cuando sus técnicas pudieran

\footnotetext{
${ }^{4}$ Sobre la base de ese argumento descansó gran parte de la reacción humanista contra Robbe-Grillet. Sin embargo, Goldmann, partiendo del mismo análisis señaló el importante valor cognitivo que esas novelas tenían para la comprensión del mundo contemporáneo, en tanto conseguían darle una forma literaria al fetichismo de la mercancía tal como se presentaban en la era del capitalismo avanzado. Más adelante, Lienhardt sobre La Jalousie y Dhaenen sobre La maison de rendez-vous siguieron con mayor o menor fidelidad ese modelo interpretativo.
} 
circunstancialmente tocarse. Una experiencia -parecía decir Barthes- específicamente literaria se ponía en juego allí.

En algún sentido es lo que Robbe-Grillet había intentado ceñir, no siempre de forma precisa, en sus textos teóricos tempranos. Ya en su ensayo sobre En attendant Godot este parecía señalar su interés, no sobre el mundo de las cosas, sino sobre el carácter concreto del mundo. La fascinación en torno a la obra de Beckett radicaba en la novedosa presencia corporal, pesada y manifiesta de los personajes en escena, en tanto avanzaban de pronto en un sentido diametralmente opuesto de los relatos previos del irlandés. Si antes todo conducía hacia una progresiva desmaterialización del mundo, ya sea porque la degradación física de los personajes terminaba por reducirlos a una mera voz o porque el significante, alejándose vertiginosamente de la referencia, devenía exangüe; ahora los cuerpos teatrales, inmóviles y macizos, se levantaban ante el público, marcando un presente entre rutinario y eterno. Los cuerpos de Vladimir y Estragon no parecían estar ahí para protagonizar alguna aventura, revelar una verdad o denunciar algo, sino todo lo contrario: su mero ser-ahí parecía inclusive rechazar el sentido. La obra amagaba introducir algunas series, pero a cada paso las borraba, impidiendo formar temas, valores o ideologías en torno de ellas. La repetición, invariable, sin progreso, de un estribillo desesperante, al final era lo único que permanecía. De allí que Robbe-Grillet encontraba cómica, aunque perfectamente entendible, la necesidad de los hermeneutas de intentar extraer algún sentido inevitablemente exterior - de esa presencia percibida banal e insoportable. El valor de esos cuerpos, cuya historia apenas se 
dejaba entrever entre sus diálogos deshilachados, no estaba decía Robbe-Grillet - sino en su mera presencia sensible, en lo seductor y tenebroso, en el enigma sin secreto de lo que apenas se ofrecía a la vista y el oído. La renuencia a hacer de la literatura una tarea de excavación-extracción de los "viejos mitos de la profundidad" (2010, p. 53) y la afirmación por lo tanto de un mundo cuya presencia superficial parecía bastarse por sí mismo al rechazar toda significación foránea, eran ideas que Robbe-Grillet comenzaba a interrogar en la literatura más avanzada y que pretendía redirigir hacia sus propios textos.

La evidencia tangible de esos cuerpos, objetos y espacios, ya no en escena, sino en el espacio abstracto del lenguaje implicaba un desafío: ¿cómo restituir la materialidad de los objetos, evitando transformarlos en signo de otra cosa (metáforas, comparaciones, ornamentos), sino haciéndolos experimentables como puras presencias? Era precisamente la extrañeza sensible de ese mundo, hecho de formas, espesores, luces y extensiones lo que impedía — tal como apuntaba Barthes- que el lector de Robbe-Grillet ya no leyera distraídamente las descripciones, como ocurría en las novelas tradicionales, sino que comenzara a otorgarles una atención y un tiempo preciso, como si estuviera bajo un efecto hipnótico que lo hiciera saborear cada uno de los objetos, a pesar de su carácter poco espectacular y su efecto retardatario del desenvolvimiento progresivo de la anécdota. En este sentido, cuando Robbe-Grillet afirmaba que el universo de Roussel era simultáneamente "plano" y “discontinuo" (2010, p. 114), definía de forma especular su propia obra: una descripción que no solo permitía sustraer al objeto de toda concepción 
decorativa, utilitaria, simbólica o funcional, volviéndolo una presencia sensible y refractaria a toda posible recuperación que lo estabilice en un sentido determinado, sino que a su vez, al aislarlo momentáneamente de la cadena sintagmática del relato, producía un exceso que le brindaba una existencia autónoma, en la que -tal como lo popularizó Valery- el sonido entraba en tensión con el sentido. De allí que uno pueda imaginar al joven Alain leyendo Locus Solus en total estado extático ante las descripciones de las autosuficientes máquinas rousselianas, viendo con asombro cómo la transparencia de las líneas conducía repentinamente a la opacidad, el caos y el sinsentido. Quizás por eso mismo Robbe-Grillet bien podía afirmar irónicamente que los objetos no le interesaban en tanto objetos, y reírse por lo tanto del punto de vista de Sartre, ya que si el filósofo existencial decía ingenuamente en una frase de La nausée que "Si dije que la caja de mi tintero era un paralelepípedo, no dije nada sobre esta caja", él por el contrario sostenía que no es sobre la caja o de la caja de lo que había que hablar, sino que había que hablar la caja (Ricardou y Van Rossum-Guyon, 1972a, p. 214). Así como Roussel inventaba una máquina por el solo poder del lenguaje, como si esta se mantuviera en pie frágilmente por el conjunto de las palabras que la formaban, Robbe-Grillet pretendía análogamente elevar el lenguaje al estatuto de una cosa, un gesto o una emoción. Se movilizaba el deseo imposible, y aun así puesto como dirección de todas sus búsquedas, de que el lenguaje sea algo más que mero lenguaje y que, a la usanza de la música o la pintura, muestre o haga lo que las palabras dicen: no un texto sobre los celos, la perversión, el terrorismo o la 
mentira, sino un texto celoso, perverso, terrorista y mentiroso. Toda la dialéctica entre el carácter representativo y productivo del lenguaje se jugaba así al interior de la técnica misma.

Por eso el chosisme derivado del barthesianismo no hacía sino confundir los asuntos; porque si bien el propio Robbe-Grillet sostenía que su empresa consistía en "edificar un mundo sólido, evidente, inalterable [...] un mundo cuyo peso y dureza serían sin embargo irrefutables, como una especie de presencia fabulosa de la que no se podría decir otra cosa que: «está ahí» (1978, p. 88), el carácter de dicha presencia no consistía en una mera tecnología dedicada a reforzar la apariencia de realismo (aunque este fuera su efecto involuntario), sino en postular un objeto autónomo sobre el que ya no pudieran sobreimprimirse categorías sociales, psicológicas o morales dadas de antemano. El rechazo tajante de Robbe-Grillet hacia los grandes sistemas interpretativos (marxistas y freudianos) no hacía sino reforzar esa idea: al señalar el modo en el que estos reducían la singularidad de los fenómenos a la generalidad de los conceptos, Robbe-Grillet no hacía sino trasladar - y he aquí una de las hipótesis claves de sus ensayos — la concepción general planteada sobre lo cósico a la obra de arte en su totalidad. El giro hacia el objeto tenía un sentido literal, pero sobre todo también uno hermenéutico: lo que este hacía aparecer era una nueva — para decirlo en términos adornianos_ "libertad para el objeto" (2011, p. 364) en la que el sujeto era invitado a entregarse o mimetizarse con la obra como si esta fuera una cosa en el mundo, con el propósito de que esta, liberándose de las exigencias de representación y significación del mundo 
exterior, comience a hablar por sí misma a través de su propia configuración formal autónoma.

No es casual por lo tanto que la tentativa insistente de Robbe-Grillet por producir un saber inmanente o intratextual haya sido contemporánea a las búsquedas estructuralistas, a los intentos de justificar científicamente los estudios literarios en tanto disciplina y postular a partir de los textos literarios una serie de métodos, saberes, procedimientos o categorías específicas. ${ }^{5}$ En definitiva, era la propia literatura la que debía extraer su comentario y exégesis de sí misma, la que debía producir un saber formal que no deba en nada a criterios extratextuales o ciencias limítrofes que utilicen a esta como mero insumo intercambiable para el conocimiento. En la búsqueda de una literatura nueva, una forma nueva para un mundo y un hombre nuevo, Robbe-Grillet no hacía sino postular otros modos específicos de entablar relaciones con ella. De allí que no haya nada más divertido — siguiendo esta idea- que leer los famosos coloquios de Cerisy prestando atención a los comentarios que este realizaba posteriormente a cada ponencia dedicada a comentar su obra u otra de algún nouveaux romancier. Desde el exacto momento en el que un sociólogo tomaba la palabra uno ya podía imaginar, sentir o prácticamente oír el tono sardónico con el que Robbe-Grillet iba a despacharlo, señalarle las limitaciones de su lectura, el desprecio que evidenciaba por los aspectos formales de sus

\footnotetext{
${ }^{5}$ No es casual tampoco que muchos de los teóricos y críticos de la época (Eco, Genette, Dallenbach) hayan utilizado sus novelas como verdaderos modelos para comenzar a pensar los problemas macroestructurales de la literatura, en tanto éstas eran ricas en procedimientos e invenciones (repeticiones, elipsis, heterocronías, mise en abyme, variaciones del punto de vista).
} 
libros y, en el límite, su indiferencia hacia la literatura en general. Sin embargo, que este rechace una lectura que busque en sus novelas la comprobación de un fenómeno externo es francamente esperable, ${ }^{6}$ pero no lo era tanto que comience dudar, como pasó a mitad de los años setenta, acerca de la pertinencia, efectividad y alcance del análisis estructural que antes había defendido con entusiasmo.

Para mí, es más bien como si nunca se hubiera dicho nada. Evidentemente, prefiero leer los análisis estructurales contemporáneos antes que las elucidaciones psicológicas o caracterológicas de épocas pasadas, sigue siendo un discurso del que no se podría prescindir pero que nunca sería más que una especie de paralelo al texto. Es como si nadie hubiera hablado del texto en sí, y alguien, quizás, lo fuera hacer algún día (Robbe-Grillet en Ricardou y Van Rossum-Guyon, 1976, p. 56).

A pesar de la influencia decisiva que habían tenido las teorías estructurales de Ricardou para la construcción de una teoría común del nouveau roman y de funcionar inclusive como inspiración para la propia invención de procedimientos novelescos, en el coloquio de 1977 Robbe-Grillet señalaba una divergencia, sutil pero fundamental, en torno a los modos de leer, que terminaría por alejarlo de aquel que había sido su camarada teórico por más de una década. La idea de que el texto crítico opera como un discurso paralelo que no alcanza a tocar o decir nada significativo sobre el texto en cuestión era

\footnotetext{
6 “Un día, él [Goldmann] me dijo a propósito de La jalousie: 'Es la cosificación'. Es así que me pareció entonces que no tenía sentido escribir la novela, porque las tesis de Lukàcs sobre este tema son mucho más claras que las de La jalousie" (Robbe-Grillet en Ricardou y Van Rossum-Guyon, 1972a, p.179).
} 
una crítica feroz (a pesar del intento de morigerar esa impresión) que anunciaba el fracaso del proyecto teórico estructuralista. El rechazo a la reducción de la experiencia literaria a una mera combinatoria formal- lingüística daba la pauta que inclusive aquella lectura que se pretendía inmanente podía volverse tan extranjera al texto como aquella que postulaba de entrada su exterioridad. Ambas se convertían finalmente en meta-lenguaje: desdoblándose, no hablaban realmente el lenguaje de la novela. El descontento entonces parecía ir más allá: a pesar del interés que sentía por el trabajo conceptual, por el devenir sistemático de la crítica literaria, el entusiasmo que expresaba frente a casi toda teoría científica nueva que se le cruzara por el camino (podía ir de la lingüística a la termodinámica, pasando por la teoría de la información a la fenomenología, siempre para precisar una particularidad de una novela, propia o ajena) y su voluntad narcisista-juguetonacolonizadora que le permitía no solo seguir con atención todo lo que se decía sobre él, sino interiorizar teóricamente todas las críticas a sus propias obras que le parecían productivas (no solo incorporaba y manipulaba las lecturas ajenas que le agradaban como si fueran propias, sino que inclusive las negativas o las erróneas eran retenidas como anécdotas que ilustraban una idea en un ensayo o entrevista posterior), ${ }^{7}$ reconocía que finalmente estas no tenían para él ningún valor de verdad particular, sino que eran meros acercamientos provisorios destinados a poner en movimiento una obra $y$ luego a ser reemplazadas cuando su función se haya agotado.

\footnotetext{
${ }^{7}$ Rybalka ha analizado algunos de esos procedimientos de apropiación, resignificación y tergiversación a los que Robbe-Grillet somete a la crítica (en Oppenheim, 1986, p. 41).
} 
El concepto funciona - no se cansaba de repetir — según la ideología o la racionalidad dominante de la sociedad y no parece tener otro destino que terminar por abstraer, unificar, inmovilizar —a los fines de la comprensión tranquilizadora lo que en la narración se presenta como un movimiento incesante de multiplicidades perturbadoras. Es por ello que, a pesar de estar advertido de estos peligros e intentar por todos los medios evitarlos, cuando daba clases de literatura en las universidades norteamericanas encontraba el mismo fondo de insatisfacción:

Comencé estos cursos de literatura [...] leyendo dos o tres páginas de una novela en voz alta [...] Luego, como todo buen analista, aporté lecturas, esto es, ya no la lectura de las palabras, sino un recorrido dentro del texto, luego una segunda, luego una tercera... del sentido en suma, temático, estructural, etc. Un sentido se desvanecía cada vez frente a otro que venía después. Así tuve la sensación de que poco a poco iba haciendo progresar a los alumnos que me escuchaban $y$, al final de cuenta, habiendo puesto todo en la clase, acabé releyendo el texto por última vez, pura y simplemente, como si cualquier enseñanza teórica del texto no se encontrara sino en el texto mismo, y nunca por otra formulación que hubiera explicado, si no sustituido el texto (en Ricardou y Van Rossum-Guyon, 1976, p. 56).

Entre la novela y el comentario se abre de pronto un abismo, una incompatibilidad total entre discursos, como si en el extremo ninguna explicación pudiera restituir el encanto inicial de la lectura, sino que dejara constantemente en evidencia su insuficiencia frente al texto. Coqueteando con el antiintelectualismo, Robbe-Grillet podía llegar incluso a sostener que "cuando me encuentro con un texto que me 
habla directamente, con el que mantengo relaciones sensuales, a menudo tengo menos ganas de analizarlo que de aprenderlo de memoria" (en Ricardou y Van Rossum-Guyon, 1976, p. 55). Nos enfrentamos así al demonio de la tautología: o queriendo respetar la inmanencia del texto el crítico académico termina por repetirlo con herramientas que no hacen sino reducir su excedente retórico, o queriendo retener su relación afectiva el lector ingenuo termina por hacer abstracción del significado contentándose con meramente repetirlo para sí. La pregunta pareciera ser entonces cómo hacer para mantener, extender e intensificar las relaciones sensuales que tenemos con los textos que nos apasionan. Es precisamente lo que Robbe-Grillet reprochaba a Morrissette: en el libro del norteamericano dedicado a su obra temprana este reconstruía con paciencia los sentidos, develaba las estructuras, indicaba arquetipos, señalaba continuidades culturales y aportaba "claves" para la comprensión; volvía -en suma- sus novelas algo perfectamente legible. Bajo su trabajo preciso y competente el misterio de la obra era aquello que había que resolver, no algo en lo que había que perderse. Es por eso que, a pesar de reconocer sus virtudes, Robbe-Grillet admitía sin dudarlo que el valor diferencial de los ensayos de Barthes o Blanchot con respecto aquel estribaba, menos en la precisión de los análisis, que en el hecho de que los franceses hacían jugar la subjetividad y la invención (2005, p. 183). En su intento de intervenir lo menos posible en el objeto que observaba, Morrissete no dialogaba con el texto, no seguía sus movimientos, no correspondía con sus maneras; no permitía, en definitiva, que la tan mentada estructura lo afectara. La relación de la literatura y la crítica 
depende de esa posibilidad de afectar y ser afectado. Es lo que Robbe-Grillet reconocía en la escritura de Barthes bajo las figuras del "temblor" y el "desplazamiento": el movimiento constante del concepto por dar cuenta de la marca que la materia tratada ha dejado en la sensibilidad (2009, p. 21). No en otro sentido señalaba en el medio del coloquio que

Me alegro de que Ollier haya hablado de contacto sensible, incluso sensual, con la frase; es algo de lo que no se ha hablado aquí, porque es aún más difícil de analizar que las estructuras de la narración; pero es cierto que hay una materialidad, una carne del texto que provoca una impresión casi física desde las primeras lecturas de algunas líneas de un escritor. Es vergonzoso decirlo en una conferencia de especialistas en composición: a veces, nos informamos más leyendo una frase, sin comprender su funcionamiento ni nada del mismo orden, simplemente por esta materialidad del texto (en Ricardou y Van RossumGuyon, 1972b, p. 283).

De allí que al ser interrogado sobre el uso de algunas imágenes en sus películas, Robbe-Grillet señalaba que a veces algunas de ellas no funcionaban como generadores estructurales ni mucho menos a la manera de temas literarios, sino que las filmaba por razones más oscuras y a su vez más simples: "El fuego, por ejemplo, es posible que ustedes lo sientan como un tema literario, pero es la belleza del fuego filmado lo que me interesó" (Ricardou y Van Rossum-Guyon, 1972a, p. 205). El carácter puramente sensible del fuego — sus ruidos y sus imágenes, sus flamas y sus crepitaciones — se vuelve una presencia fascinante y prácticamente irrecuperable para quien quiera extraer de él un saber sólido, un instrumento para 
ejercer la crítica de los mitos e ideologías del presente. Todo el trabajo de la crítica literaria no es más que el deseo desmesurado e irracional de decir esa fascinación; pero si el positivismo apaga el fuego y edifica sobre las cenizas, el ensayismo quiere atizarlo a riesgo de quemarse por la cercanía. Lejos de la univocidad que el crítico estructural les atribuye o proyecta, los procedimientos enredan al lector en una serie de estados contradictorios (de la euforia a la incertidumbre, de la libertad interpretativa ante lo abierto a la manipulación psicológica de un procedimiento obsesionante) que lo empujan a una experiencia sensible que desafía sus preceptos morales o cognitivos. Pero eso y no otra cosa era lo que el propio Barthes no dejaba de señalar en los textos de Robbe-Grillet: "la consecuencia es que esta mirada en ningún aspecto puede hacer reflexionar: no puede recuperar nada del hombre" (1973, p. 122). Si la fábula novelesca por lo tanto instaura una dirección univoca, acumula sentido y lo proyecta utilitariamente hacia la vida, el instante objetual y epifánico es la interrupción soberana que permite apreciar algo diferente: una experiencia intensa, indeterminada, específica. Experiencia que ambos, con equívocos, tanteos y rodeos, no hicieron sino perseguir.

\section{Referencias Bibliográficas}

Adorno, T. (2011 [1970]). Teoría estética. Madrid: Akal.

Barthes, R. (1973 [1964]). Ensayos críticos. Barcelona: Seix Barral.

---. (2003 [1961]). Variaciones sobre la literatura. Buenos Aires: Paidós. 
---. (2010 [1971]). Crítica y verdad. Buenos Aires: Siglo XXI.

Genette, G. (1970 [1966]). Figuras I. Córdoba: Nagelkop.

Jost, F. (ed.) (1978). "Lettre à Emile Henriot". Obliques, 16-17, París: Borderie.

Oppenheim, L. (ed.) (1986). "Alain Robbe-Grillet: at play with criticism". Three decades of the French new novel. Chicago: Illionis Press.

Ricardou, J. y Van Rossum-Guyon, F. (ed.). (1972a). Nouveau Roman: hier, aujourd'hui. 1. Problèmes généraux, París: Union Générale D'Éditions.

---. (1972b). Nouveau Roman: hier, aujourd'hui. 2. Problèmes généraux, París: Union Générale D’Éditions.

---. (1976). Robbe-Grillet: analyse, théorie. Vol. 1. París: Union Générale D'Éditions.

Robbe-Grillet, A. (1969 [1955]). El mirón. Barcelona: Seix Barral.

---. (2001). Le voyageur. París: Christian Bourgois.

---. (2005). Préface a une vie d'écrivain. París: Seuil.

---. (2009 [1978]). Pourquoi j’aime Barthes. París: Christian Bourgois.

---. (2010 [1963]). Por una nueva novela Buenos Aires: Cactus.

Fecha de recepción: 11/05/2021

Fecha de aprobación: 22/06/2021 